RMD

Open

Rheumatic \&

Musculoskeletal

Diseases

To cite: Westhovens $\mathrm{R}$, Annemans L. Costs of drugs for treatment of rheumatic diseases. RMD Open 2016;2: e000259. doi:10.1136/ rmdopen-2016-000259

- Prepublication history for this paper is available online To view these files please visit the journal online (http://dx.doi.org/10.1136/ rmdopen-2016-000259)

Received 11 May 2016 Revised 19 July 2016 Accepted 21 July 2016

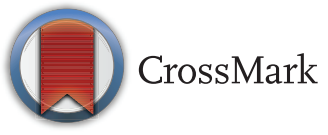

${ }^{1}$ Department of Development and Regeneration, Skeletal Biology and Engineering Research Center KU Leuven, Rheumatology University Hospital Leuven, Leuven, Belgium

${ }^{2}$ Department of Public Health, I-CHER Interuniversity Centre for Health Economics Research, Ghent University, Ghent, Belgium

Correspondence to Dr Rene Westhovens; rene.westhovens@uzleuven. be

\title{
Costs of drugs for treatment of rheumatic diseases
}

\author{
Rene Westhovens, ${ }^{1}$ Lieven Annemans ${ }^{2}$
}

\section{ABSTRACT}

The cost of drugs is becoming an issue worldwide, in particular for inflammatory rheumatic diseases. In the current review, an overview of the scene is given with a specific emphasis on accessibility for those patients in real need of the available expensive treatments. The authors propose 7 principles for discussion that need to be addressed and are a responsibility for all stakeholders in rheumatology.

\section{INTRODUCTION}

The past two decades have witnessed an unprecedented and impressive improvement in the therapy of many rheumatic diseases, more specifically chronic inflammatory conditions such as rheumatoid arthritis (RA) and spondyloarthritis (SpA). Earlier, more targeted treatment and also new drugs-the biological disease-modifying antirheumatic drugs (bDMARDs) - have contributed to this and have definitely changed the lives of many patients. This has been associated with an important increase in costs for treatment, especially direct drug costs. In Belgium (11 million inhabitants), adalimumab and etanercept were number 1 and 2 respectively in the list of top expenditures for all ambulatory reimbursed medicines in 2014. Both medicines together are responsible for an annual expenditure of $\pm € 190$ million and showed a mean yearly increase over the past 4 years of $\pm € 8.5$ and $€ 3$ million for adalimumab and etanercept, respectively. About 18000 patients are treated with these drugs yearly, whereby $50 \%$ of adalimumab and $85 \%$ of etanercept were prescribed by rheumatologists. ${ }^{1}$ In Australia, the government expenditure on bDMARDs has increased to $\$$ A383 million in 2014; moreover, the newer biologicals, tocilizumab, golimumab and certolizumab pegol, contributed \$A9 million in 2014 $-210 \%$ over the initial estimates. ${ }^{2}$ Also in the USA, these high-cost specialty drugs for RA put an important burden on the system. ${ }^{3}$
A recent study on healthcare use and direct costs in patients with ankylosing spondylitis and psoriatic arthritis in the USA identified, besides age and comorbidities, bDMARDs as the major determinant of all cause direct costs. ${ }^{4}$ Prescription drug annual costs were higher for psoriatic arthritis than ankylosing spondylitis, with a mean of US\$14 174 (SD 15 821) and US $\$ 11214$ (SD 14 249), respectively. Given the budget restrictions in many countries, in addition to lack of availability of drugs in other countries as well as migration issues, it is a time to reflect on the costs of drugs for effectively treating rheumatic conditions. The authors of this review want to give points to consider for the future rather than suggesting a solution or taking a firm position. In recent years, colleagues from the haematological/cancer field took more firm viewpoints, ${ }^{5}$ blaming the innovative industry for unsustainable pricing. We will not discuss here whether one disease is worth a higher price than another, although this is also a debate that must be held. Indeed, discussions are coming up about the value of adding some months to life in certain bad prognosis cancers or the value of treating patients with very rare diseases for a very high price, sometimes without convincing scientific data.

The points we offer for consideration are more directly related to the field of rheumatology. The idea is that within this field, a higher quality of care can be achieved at a lower cost. Rheumatologists have a tradition of caring for patients, trying to improve function and quality of life, and over the past two decades the evidence on how to achieve this has also increased. In Belgium, currently 10 bDMARDs are available and number 11, the first biosimilar of etanercept, will probably be added at the end of 2016. So rheumatologists are also confronted with a wealth of choice, and this while there is no evidence on a group level that one bDMARD is better than the other. Surely differences might be seen for individual patients, but they cannot be 
predicted. An interesting investigator initiated randomised study conducted in the Netherlands and Belgium in patients refractory to a first tumour necrosis factor (TNF) blocker found no difference in efficacy between a second TNF blocker or abatacept or rituximab but stated that when costs are important to consider, one would need to make the choice for rituximab just because this drug is cheaper. ${ }^{6}$ Let this now be the drug that is not really promoted anymore, probably because the patent already has expired more than 2 years ago. Moreover, in contrast with some TNF blockers of which the patent expired later, the first biosimilar of rituximab will not yet be available this year. The pricing at an almost equal level between different agents is a stunning finding and the lower price of rituximab is of course related to the previous use of this drug in other (haematological) indications.

In general, pricing of medicines depends on six different factors.

1. The costs of manufacturing, research and development (R\&D) (including failures), marketing and promotion, overheads, distribution;

2. The expected market size (the smaller the market size, the higher the price in order to recoup the relatively higher fixed costs of development);

3. The costs of current treatment, which serves as a reference point;

4. Price elasticity of demand, that is, how sensitive to pricing is a given market or a given disease area;

5. Prevailing price regulations and pricing policies;

6. The value of the benefits of the product.

Given these factors, and given the aim of achieving a higher quality of care at a lower cost, we present below some principles to be ideally applied as a way forward.

\section{VALUE OF THE BENEFITS TO BE REFLECTED IN PRICING}

Valuing the benefits of products (factor 6 above) is a justified approach and helps to stimulate research into innovation. Indeed, if better value is better rewarded, this stimulates the innovative industry to develop new medicines with added value. Yet when the value in realworld practice is not as good as expected, arrangements should be made possible as to recover part of the money that governments or health insurers have spent. In some disease areas, such outcomes based risk sharing agreements are upcoming, but not yet in the field of RA.

Principle 1: Outcomes based pricing should be applied in a dynamic way such that unsatisfactory outcomes are less rewarded.

\section{DECREASING MEDICAL NEEDS AND PRICING}

It is interesting to observe that in the field of rheumatology (as in different other fields) a new drug that enters a saturated market with a same or different mechanism of action, but with equal effectiveness, is almost never cheaper than the already available drugs. Yet one could argue that with the decreasing medical need as well as with the increasing volumes in sales in new indications and in patients with less severe disease, these prices should go down. All data from trials and daily practice cohorts indicate that current patients have a clearly less severe disease state and the dramatic joint damage that was still feared two decades ago is now rare, certainly in wealthier countries.

Principle 2: Decreasing medical need and increasing volumes should be associated with lower prices.

\section{ACCESSIBILITY MADE POSSIBLE BY DIFFERENTIAL PRICING}

Meanwhile, access to biological therapies is a problem in many parts of the world and a responsible physician has to bear this in mind. A specific working group studied this issue in Europe and found, not surprisingly, regulations regarding market access of disease-modifying antirheumatic drugs (DMARDs) to be more restrictive in less wealthy countries. The lower the country's welfare level (as measured by gross domestic product (GDP) per capita), the higher the required disease activity scores for accepting access of bDMARDs. ${ }^{7}$ The authors find this alarming as stricter clinical eligibility criteria seem to also be associated both with lower uptake of biologics and with higher disease activity, thus suggesting that principles of equitable healthcare systems might be undermined within Europe.

Principle 3: In clusters of countries with a lower GDP per capita, prices of valuable medicines should be proportionally lower.

This differential pricing approach can be achieved by agreements between countries to not apply price referencing policies between each other and by not allowing parallel trade. This could be defended despite European regulations on free market mechanisms, since the latter must be overruled by public health interest. Yet in a recent study comparing countries in eastern Europe, per capita GDP did not explain all differences in access ${ }^{9}$ making clear that the cost of the drug in relation to the welfare level does not need to be the only focus when aiming for improvement in access.

\section{BETTER MODALITIES OF USE FOR OLD AND NEW DRUGS}

Other cost elements may be related to the modalities of new medicines and their use in daily practice. When a new drug treatment is coming to the market, efficacy and safety as well as speed of response, sustainable response, effectiveness in using the new drug in a treat to target strategy, possibilities of tapering, ${ }^{10}$ easy administration and follow-up are all important. Here, independent research funded by governments could lead to better insights, and this both for new incoming drugs as well as for those already available for many years such as methotrexate or glucocorticoids.

Principle 4: The expenditure on medicines can be reduced by better modalities of use. 


\section{PRICE COMPETITION IS NEEDED}

Innovative thinking is also required when positioning a new drug. Currently a new drug is often positioned in the same treatment phase (first or second line) as a competitor and this at the same price. Bringing that drug earlier in the treatment cascade would not be possible for that price. So there is a need for innovative pricing strategies.

A cheaper drug that has equal activity as a current expensive bDMARD could perhaps gain an important part of the current market that certainly in the Western world is not expected to grow endlessly. Many of us are critically looking at how the new oral (less production costs?) Janus kinase (JAK) inhibitors will be priced in this regard. Some might state that prices of bDMARDs are already going down because of biosimilars becoming available. In Belgium, indeed, every bio-original with a biosimilar available will need to decrease its price to the same level of the biosimilar. This implies a fair penetration of biosimilars in every country; otherwise, this mechanism will not be activated. In Belgium, a specific convention stimulated by the government is signed between pharmaceutical industry and professional organisation to allow this penetration of biosimilars into the market. Hence, this is also a call to European member states to work more closely together regarding pricing policies. Although pricing is a competence of each individual member state, working together could lead to better agreements with the industry.

Principle 5: New drugs coming into the market, without added benefit, should automatically be priced lower. A price competition process may be installed.

\section{A LOWER PRICE DOES NOT MEAN UNRESTRICTED USE}

On the other hand, it will not be a good idea to loosen the restrictions for reimbursement too much: lower prices leading to unnecessary increased use in some indications could lead to even increased costs in those indications. The current debate about classifying nonradiographic SpA is exemplary and important for this principle.

Principle 6: The availability of biosimilars should not lead to loosening completely the restrictions for reimbursement.

\section{A DIFFERENT FOCUS ON COST-EFFECTIVE USE OF DRUGS AND THEIR EVALUATION IS MANDATORY}

Investigating predictive biomarkers to avoid unnecessary use of expensive drugs in an important number of patients... and perhaps a marker or a strategy that avoids the start of an expensive drug without loss in quality outcome would be of help. Once a patient is started on a bDMARD, the chance currently is high that he or she will continue on such an expensive drug. Markers that would indicate possibilities to stop or taper expensive drugs and would allow to continue on less expensive options are welcome. Moreover cost-effectiveness studies should evaluate what happens in daily practice and at least a correct comparator should be used, that is, combination therapy in a treat to target setting and not methotrexate (MTX) monotherapy versus biologics in early DMARD naïve RA. ${ }^{11}$

Cost-effectiveness analysis of a biological in the past was classically based on randomised controlled trial (RCT) data required for registration purposes, that is, in MTX refractory patients adding a biological or continuing MTX. ${ }^{12}$ One might discuss the definition of an MTX refractory status, but even more important, no clinician would just continue an insufficient treatment for another year. Wolfe and Michaud ${ }^{13} 14$ already discussed the issue of overestimation of treatment response and effectiveness more than a decade ago. They pointed to the flare state of patients included in trials as the major driver in this overestimation, while certainly also just participating in a trial might increase treatment response (Hawthorne effect). Instead of evaluating within patients changes they propose to analyse symptoms and function in a broader (RA) population, a new treatment that is introduced should have a benefit on the disease burden independent of patient selection and timing of therapy. The same authors modelled the progression of loss of health status and measured incremental costs and effectiveness in the community over a 10-year observation period using data from the National Data Bank for Rheumatic Diseases in the USA and found clearly less impressive costeffectiveness figures than those derived from RCTs. ${ }^{15}$

Principle 7: Biomarker research could be expanded towards health-economic evaluations and these evaluations should use the correct comparator and correct methodology.

\section{CONCLUSIONS}

It is clear that the pharmaceutical industry has the right to get a correct price for all innovative research in all fields taking into account even risks of unexpected failures and correct marketing efforts. The ultimate goal of an innovative drug lies in improvement of patients' lives. How a drug is used, in which strategy, with correct precautions and optimal care is, however, as important in a new treatment as the intrinsic quality of a drug.

Accessibility for the real patients in need, and avoiding use by those who are not in need is key. Thereby, a fair price is also a matter of interest for a pharmaceutical company.

This said, we cannot stress enough that every rheumatologist has in this also an important task. Prescribing drugs, and specifically expensive drugs, only where needed and associated with optimal care for the patients, considering tapering expensive drugs where needed and possible, contributing to independent research aiming at an optimal outcome for every individual involved, cannot be achieved without a realistic and responsible view on the costs.

Altogether, the pharmaceutical industry, caregivers, payers and regulators, and also patients need to take a responsible position in this matter. We will need to be 
transparent in discussions on a morally just price, with all data in hand and with respect of all positions. Correct investments in correct trials are needed. ${ }^{16}$

Competing interests RW received unrestricted research grants to his institution from Roche and participated in a speakers bureau for BMS. RW acted as a principal investigator for Jansen and Galapagos.

Provenance and peer review Commissioned; externally peer reviewed.

Data sharing statement No additional data are available.

Open Access This is an Open Access article distributed in accordance with the Creative Commons Attribution Non Commercial (CC BY-NC 4.0) license, which permits others to distribute, remix, adapt, build upon this work noncommercially, and license their derivative works on different terms, provided the original work is properly cited and the use is non-commercial. See: http:// creativecommons.org/licenses/by-nc/4.0/

\section{REFERENCES}

1. http://www.riziv.fgov.be/nl/publicaties/Paginas/infospot

2. Hopkins AM, Proudman SM, Vitry Al, et al. Ten years of publicly funded biological disease-modifying antirheumatic drugs in Australia. Med J Aust 2016;204:64-8.

3. Yazdany J, Dudley RA, Chen R, et al. Coverage for high-cost specialty drugs for rheumatoid arthritis in Medicare Part D. Arthritis Rheumatol 2015:67:1474-80.

4. Greenberg JD, Palmer JB, Li Y, et al. Healthcare resource use and direct costs in patients with ankylosing spondylitis and psoriatic arthritis in a large US cohort. J Rheumatol 2016:43:88-96.

5. Experts in Chronic Myeloid Leukemia. The price of drugs for chronic myeloid leukemia (CML) is a reflection of the unsustainable prices of cancer drugs: from the perspective of a large group of CML experts. Blood 2013;121:4439-42.
6. Manders SH, Kievit W, Adang E, et al. Cost-effectiveness of abatacept, rituximab, and TNFi treatment after previous failure with TNFi treatment in rheumatoid arthritis: a pragmatic multi-centre randomised trial. Arthritis Res Ther 2015;17:134.

7. Putrik P, Ramiro S, Kvien TK, et al. Inequities in access to biologic and synthetic DMARDs across 46 European countries. Ann Rheum Dis 2014;73:198-206.

8. Putrik $\mathrm{P}$, Ramiro $\mathrm{S}$, Kvien TK, et al. Variations in criteria regulating treatment with reimbursed biologic DMARDs across European countries. Are differences related to country's wealth? Ann Rheum Dis 2014;73:2010-21

9. Gulácsi L, Rencz F, Poór G, et al. Patients' access to biological therapy in chronic inflammatory conditions; per capita GDP does not explain the intercountry differences. Ann Rheum Dis 2016;75:942-3.

10. Fautrel $B$, den Broeder AA. De-intensifying treatment in established rheumatoid arthritis (RA): why, how, when and in whom can DMARDs be tapered? Best Pract Res Clin Rheumatol 2015;29:550-65.

11. Verschueren $\mathrm{P}$, Westhovens R. Optimal care for early RA patients: the challenge of translating scientific data into clinical practice. Rheumatology (Oxford) 2011;50:1194-200.

12. Vera-Llonch M, Massarotti E, Wolfe F, et al. Cost-effectiveness of abatacept in patients with moderately to severely active rheumatoid arthritis and inadequate response to methotrexate. Rheumatology (Oxford) 2008;47:535-41.

13. Wolfe F, Michaud K, Dewitt EM. Why results of clinical trials and observational studies of antitumour necrosis factor (anti-TNF) therapy differ: methodological and interpretive issues. Ann Rheum Dis 2004;63(Suppl 2):ii13-17.

14. Wolfe F, Michaud K. Towards an epidemiology of rheumatoid arthritis outcome with respect to treatment: randomized controlled trials overestimate treatment response and effectiveness. Rheumatology (Oxford) 2005;44(Suppl 4):iv18-22.

15. Wolfe $F$, Michaud $K$. The loss of health status in rheumatoid arthritis and the effect of biologic therapy: a longitudinal observational study. Arthritis Res Ther 2010;12:R35.

16. Bansback N, Keystone E, O'Dell J, et al. Making smart investment decisions in clinical research. Trials 2015;16:590. 